\title{
Composite Materials Based on Henequen Fiber as a Thermal Barrier in the Automotive Sector
}

\author{
J. M. Olivares-Ramírez $\left(\mathbb{D},{ }^{1}\right.$ A. Dector $\mathbb{D}^{2},{ }^{2}$ A. Duarte-Moller $\mathbb{D}^{3,4}{ }^{3,}$ D. Ortega Díaz, ${ }^{5}$ \\ Diana Dector, ${ }^{3}$ J. A. Cano-López, ${ }^{3}$ R. Rangel-Martínez, ${ }^{1}$ J. J. Pérez-Bueno ${ }^{D}{ }^{5}$ \\ A. Castañeda-Miranda $\mathbb{D}^{6}{ }^{6}$ and Felipe Samuel Tovar-Pacheco ${ }^{1}$ \\ ${ }^{1}$ Universidad Tecnológica de San Juan del Río, Col. Vista Hermosa, San Juan del Río, 76800 Querétaro, Mexico \\ ${ }^{2}$ CONACYT-Universidad Tecnológica de San Juan del Río, Col. Vista Hermosa, San Juan del Río, 76800 Querétaro, Mexico \\ ${ }^{3}$ Centro de Investigación en Materiales Avanzados, Complejo Industrial Chihuahua, 31109 Chihuahua, Mexico \\ ${ }^{4}$ Universidad de La Salle Bajío, Escuela de Ingeniería, Av. Universidad 602, Col. Lomas del Campestre, 37150 León, \\ Guanajuato, Mexico \\ ${ }^{5}$ Centro de Investigación y Desarrollo Tecnológico en Electroquímica, Parque Tecnológico Querétaro, 76703 Querétaro, Mexico \\ ${ }^{6}$ Centro de Física Aplicada y Tecnología Avanzada, Universidad Nacional Autónoma de México, Boulevard Juriquilla, \\ 76230 Querétaro, Mexico
}

Correspondence should be addressed to J. M. Olivares-Ramírez; jmolivar01@yahoo.com and A. Dector; andres_dector@live.com

Received 5 February 2019; Revised 6 March 2019; Accepted 10 March 2019; Published 14 July 2019

Academic Editor: Gang Zhang

Copyright ( 2019 J. M. Olivares-Ramírez et al. This is an open access article distributed under the Creative Commons Attribution License, which permits unrestricted use, distribution, and reproduction in any medium, provided the original work is properly cited.

\begin{abstract}
Currently, the automotive industry has made great advances in the incorporation of materials such as carbon fiber in highperformance cars. One of the main problems of these vehicles is warming, which is generated inside due to the heat transfer produced by solar radiation falling on the car, mainly on the roof. This research proposes the preparation of a composite material containing henequen natural fiber as a thermal barrier to be used as the roof of the car. In this research, 35 different laminates of 5 layers were prepared, combining carbon fiber, henequen natural fiber, fiberglass, and additives such as resin $+\mathrm{Al}_{2} \mathrm{O}_{3}$ or resin $+\mathrm{Al}$. Reference samples were taken from stainless steel and one reference sample was extracted from the roof of the car. Considering the solar radiation and the heat transfer mechanisms, the temperature of the surface exposed to solar radiation was determined. The thermal conductivity of the 37 samples was determined, and the experimental results showed that the thermal conductivity of the steel with which the roof of the car is manufactured was $13.43 \mathrm{~W} \cdot \mathrm{m}^{-1} \cdot \mathrm{K}^{-1}$ and that of the proposed laminate was $5.22 \mathrm{~W} \cdot \mathrm{m}^{-1} \cdot \mathrm{K}^{-1}$, achieving a decrease in the thermal conductivity by $61.13 \%$. Using the temperature and thermal conductivity data, the simulation (ANSYS) of the thermal system was performed. The results showed that the temperature inside the car with the carbon steel, which is currently used to manufacture high-performance cars, would be $62.34^{\circ} \mathrm{C}$, whereas that inside the car with the proposed laminate would be $44.96^{\circ} \mathrm{C}$, achieving a thermal barrier that allows a temperature difference of $17.38^{\circ} \mathrm{C}$.
\end{abstract}

\section{Introduction}

The current technological breakthrough in many areas of research and industry has opened the need to look for new materials that have greater benefits than the materials that are commonly used in different applications. In this context, researchers from all over the world have innovated different material systems. Composites being one of the most prominent material systems. These composites are made of two or more constituents [1], bringing as a consequence that each composite offers unique advantages by complementing each constituent with another.

For example, the incorporation of polymeric resins, metals, or metal oxides into matrices based on carbon fiber, 
fiberglass, and even natural fibers has advantages in hardness, tensile strength, modulus of elasticity, and other mechanical properties. In addition, other properties can be decreased and/or improved such as thermal conductivity, the coefficient of thermal expansion, the coefficient of friction, wear resistance, corrosion, and fatigue resistance $[2,3]$.

Currently, in the automotive and aeronautical industries, thermomechanical properties have acquired great importance due to the different components used in these systems. In this sense, composites based on graphene, carbon fiber, fiberglass, and natural fibers have explored new applications in these two areas ranging from the manufacture of parts that constitute the external or internal structure of automobiles and aircraft and the electronic application that helps to protect and, at the same time, dissipate the heat [4-11].

Carbon fiber is considered one of the coal-based materials with excellent mechanical properties and chemical stability. Normally, this material contains 92 wt.\% of carbon in each of its fibers [12]. These fibers offer very good mechanical and physical properties [13-16], for example, high tension $(2-7 \mathrm{GPa})$ by having a remarkable Young modulus (200-900 GPa), low density $\left(1.75-2.20 \mathrm{~g} \cdot \mathrm{cm}^{-3}\right)$, low thermal expansion, and excellent electrical conductivity and thermal conductivity $\left(800 \mathrm{~W} \mathrm{~m}^{-1} \cdot \mathrm{K}^{-1}\right)[8,17-21]$. In addition, carbon fiber is not only four times lighter than steel but also stronger than steel [22]. All these characteristics are the main reason that carbon fiber is used to develop lightweight composites for structural applications in the automotive and aeronautical areas [23-27].

On the contrary, fiberglass has been widely used and studied for a long time as a matrix in the manufacture of composites. One of its main advantages is the cost due to the high demand for use.

It has not been the same case for the use of natural fibers in the formation of composites, since this case is relatively new and is still being explored by researchers in the area. However, the purpose of adding natural fibers in the formation of composites has been quite attractive because it offers properties such as lightness, biodegradability [28], high strength [29, 30], high wear [31], thermal properties [32-34], good corrosion resistance [35], and low coefficient of friction [36] mainly for aerospace or automotive applications [37-45]. In this context, one of the natural fibers that have attracted the most attention in the formation of composites is the henequen Agave fourcroydes (sisal, Agave sisalana) fiber, due to the added reinforcement in the mechanical and biodegradability properties. Values of Young's modulus and tensile strength have been reported between 9.4 and $22 \mathrm{GPa}$ and between 468 and $640 \mathrm{MPa}$, respectively, for this henequen fiber [46].

The thermomechanical properties of fiber-based composites (carbon, glass, or natural fiber) depend in large part on the properties of the polymer matrices used in their construction, the properties of the constituent additives added (metals, metal oxides, or others), and the interaction between the polymer matrix, the added constituents, and the fibers used [47-49].

In this work, the thermal properties of the composites formed by carbon fiber, glass fiber, and natural henequen fiber reinforced with a polymer matrix, aluminum, and alumina $\left(\mathrm{Al}_{2} \mathrm{O}_{3}\right)$ have been investigated. Under this context, studies showed that the addition of aluminum $[25,50]$ and alumina particles in carbon fiber-based composites changes the thermomechanical properties [4].

\section{Materials and Methods}

2.1. Manufacture of Laminates. Laminates of five layers, with dimensions of $0.05 \times 0.05 \mathrm{~m}$, were prepared by the following methodology. First, a mixture of monomer (REM-001) and catalyst (HY-956) was prepared in a $4: 1$ ratio. Subsequently, with the same $4: 1$ ratio of weight, to the obtained mixture of monomer and catalyst, Al (Golden bell, aluminum 99.6\%, PM 26.98, Code 27945) or $\mathrm{Al}_{2} \mathrm{O}_{3}$ (Repasack, ground calcined alumina, $55 \times 58+13$ ) was added. Finally, this mixture of monomer + catalyst $+\mathrm{Al}$ or $\mathrm{Al}_{2} \mathrm{O}_{3}$ was used to cover the surface of each sheet used in the formation of the laminate. On the contrary, the sheets used were carbon fiber (CF), glass fiber (GF), and natural henequen fiber (NHF), as shown in Table 1.

2.2. Morphological Characterization. For morphological characterization, scanning electron microscopy (SEM) and energy-dispersive X-ray spectroscopy (EDS) were used for the determination of elements, and their percentage in weight was determined by using a Hitachi SU3500 scanning electron microscope.

2.3. Thermal Tests. For the thermal tests carried out on each laminate, the surface was standardized with a layer of insulating tape to standardize the emissivity of the surface (37 samples were coated). In these tests, the thermography was performed in $10 \mathrm{~s}$ periods for $120 \mathrm{~s}$, using an infrared camera FLIR-E6. The thermal analysis to determine the surface temperature of each laminate was through an average of 9 points visualized in the thermography and 4 points on the hot surface in which the laminate was located. The hot surface was generated by an aluminum block, $0.14 \times 0.14 \times 0.015 \mathrm{~m}$, in which the power of flat resistance was $80 \mathrm{~W}$, and was embedded, maintaining the temperature of this surface at $80^{\circ} \mathrm{C}$ by using a temperature controller (STC-1000). The hot surface was also covered with an insulating tape for uniforming the emissivity of the surface with laminate.

The solar radiation and the ambient temperature were recorded through the weather station, number 29 $\left(20^{\circ} 22^{\prime} 06.1^{\prime \prime} \mathrm{N} 100^{\circ} 00^{\prime} 34.2^{\prime \prime} \mathrm{W}\right)$, located in San Juan del Río, Querétaro, Mexico, on May 31, 2018.

A sheet of austenitic stainless steel SAE-304 (sample 36) and one sheet extracted from a roof (sample 37) of a car were used as a reference. The thermal conductivity of the 37 samples was calculated using the conduction heat transfer equation, steady state, and unidirectional flow, considering a heat flux of $80 \mathrm{~W}$, which was the power of the heating thermal resistance. A thickness of $0.0041 \mathrm{~m}$ was used for samples from 1 to 36 , and a thickness of 0.00125 was used for sample 37. 
TABLE 1: Laminate configuration: carbon fiber (CF), glass fiber (GF), and natural henequen fiber (NHF).

\begin{tabular}{|c|c|c|c|c|c|c|}
\hline \multirow[t]{2}{*}{ Additive } & \multicolumn{4}{|c|}{ Laminates } & & \multirow{2}{*}{$\begin{array}{c}\text { Sample } \\
1\end{array}$} \\
\hline & $\mathrm{CF}$ & CF & $\mathrm{CF}$ & $\mathrm{CF}$ & $\mathrm{CF}$ & \\
\hline \multirow{10}{*}{$\mathrm{Al}_{2} \mathrm{O}_{3}$} & CF & CF & $\mathrm{NHF}$ & $\mathrm{CF}$ & $\mathrm{CF}$ & 2 \\
\hline & $\mathrm{CF}$ & $\mathrm{NHF}$ & CF & NHF & $\mathrm{CF}$ & 3 \\
\hline & $\mathrm{NHF}$ & $\mathrm{CF}$ & $\mathrm{NHF}$ & $\mathrm{CF}$ & NHF & 4 \\
\hline & CF & CF & GF & $\mathrm{CF}$ & $\mathrm{CF}$ & 5 \\
\hline & $\mathrm{CF}$ & GF & $\mathrm{CF}$ & GF & $\mathrm{CF}$ & 6 \\
\hline & GF & CF & GF & $\mathrm{CF}$ & GF & 7 \\
\hline & GF & $\mathrm{CF}$ & $\mathrm{NHF}$ & GF & GF & 8 \\
\hline & NHF & CF & GF & $\mathrm{CF}$ & NHF & 9 \\
\hline & GF & $\mathrm{NHF}$ & $\mathrm{CF}$ & NHF & GF & 10 \\
\hline & NHF & GF & CF & GF & NHF & 11 \\
\hline \multirow{11}{*}{$\mathrm{Al}$} & $\mathrm{CF}$ & $\mathrm{CF}$ & $\mathrm{CF}$ & $\mathrm{CF}$ & $\mathrm{CF}$ & 14 \\
\hline & $\mathrm{CF}$ & CF & $\mathrm{NHF}$ & $\mathrm{CF}$ & $\mathrm{CF}$ & 15 \\
\hline & $\mathrm{CF}$ & NHF & $\mathrm{CF}$ & NHF & $\mathrm{CF}$ & 16 \\
\hline & NHF & CF & NHF & $\mathrm{CF}$ & NHF & 17 \\
\hline & $\mathrm{CF}$ & $\mathrm{CF}$ & GF & $\mathrm{CF}$ & $\mathrm{CF}$ & 18 \\
\hline & CF & GF & CF & GF & $\mathrm{CF}$ & 19 \\
\hline & GF & $\mathrm{CF}$ & GF & $\mathrm{CF}$ & GF & 20 \\
\hline & GF & CF & NHF & GF & GF & 21 \\
\hline & $\mathrm{NHF}$ & $\mathrm{CF}$ & GF & $\mathrm{CF}$ & NHF & 22 \\
\hline & GF & NHF & CF & NHF & GF & 23 \\
\hline & NHF & GF & CF & GF & NHF & 24 \\
\hline \multirow{11}{*}{ Only resin } & $\mathrm{CF}$ & $\mathrm{CF}$ & $\mathrm{CF}$ & $\mathrm{CF}$ & $\mathrm{CF}$ & 25 \\
\hline & $\mathrm{CF}$ & $\mathrm{CF}$ & $\mathrm{NHF}$ & $\mathrm{CF}$ & $\mathrm{CF}$ & 26 \\
\hline & $\mathrm{CF}$ & $\mathrm{NHF}$ & $\mathrm{CF}$ & NHF & $\mathrm{CF}$ & 27 \\
\hline & $\mathrm{NHF}$ & $\mathrm{CF}$ & NHF & $\mathrm{CF}$ & NHF & 28 \\
\hline & CF & CF & GF & $\mathrm{CF}$ & $\mathrm{CF}$ & 29 \\
\hline & $\mathrm{CF}$ & GF & $\mathrm{CF}$ & GF & $\mathrm{CF}$ & 30 \\
\hline & GF & CF & GF & $\mathrm{CF}$ & GF & 31 \\
\hline & GF & $\mathrm{CF}$ & NHF & GF & GF & 32 \\
\hline & NHF & CF & GF & $\mathrm{CF}$ & NHF & 33 \\
\hline & GF & $\mathrm{NHF}$ & $\mathrm{CF}$ & NHF & GF & 34 \\
\hline & $\mathrm{NHF}$ & GF & $\mathrm{CF}$ & GF & NHF & 35 \\
\hline
\end{tabular}

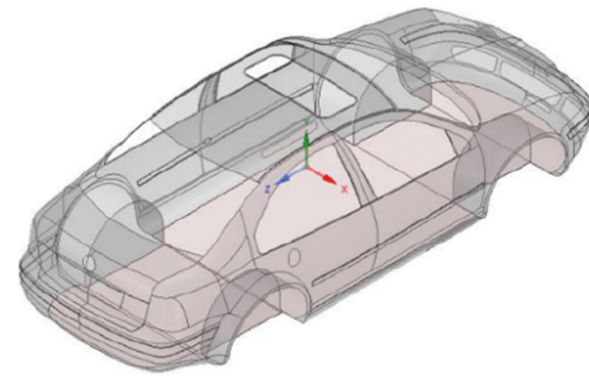

(a)

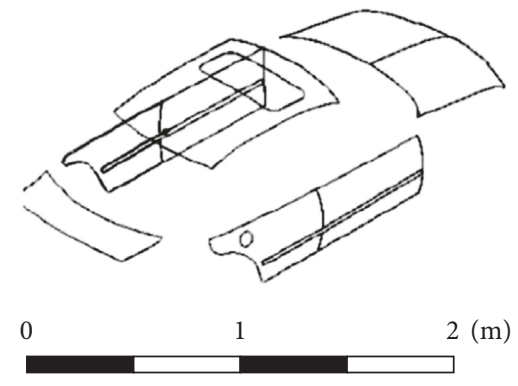

(b)

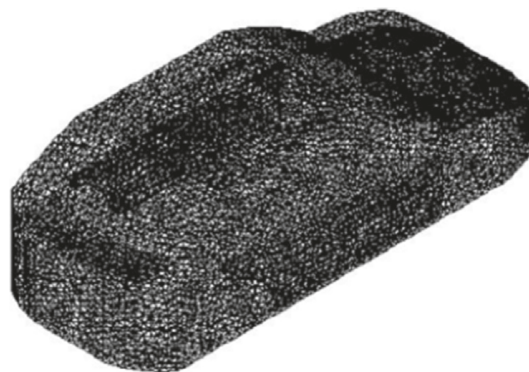

(c)

Figure 1: System mesh: (a) system surfaces, (b) surfaces considered for heat transfer, and (c) mesh volume.

In order to know the temperatures of the hot surface of each laminate, thermographies were made in these surfaces.

2.4. Simulation. In the present investigation, ANSYS workbench was used in "Steady-State Thermal" module to quantify the thermal behavior of the system.

The thermal behavior is analyzed by conservation of energy (from the first law of thermodynamics for a control volume) applied to this system as well as any system with heat transfer or energy exchange. The element equation for the analysis [51] is as follows:

$$
[K]\{T\}=\{Q\},
$$

where $[K]$ is the thermal conductivity matrix, $\{T\}$ is the column vector of nodal temperatures, and $\{Q\}$ is the column vector of nodal heat fluxes. The complete system is represented in Figure 1(a). The surfaces considered to have the greatest 


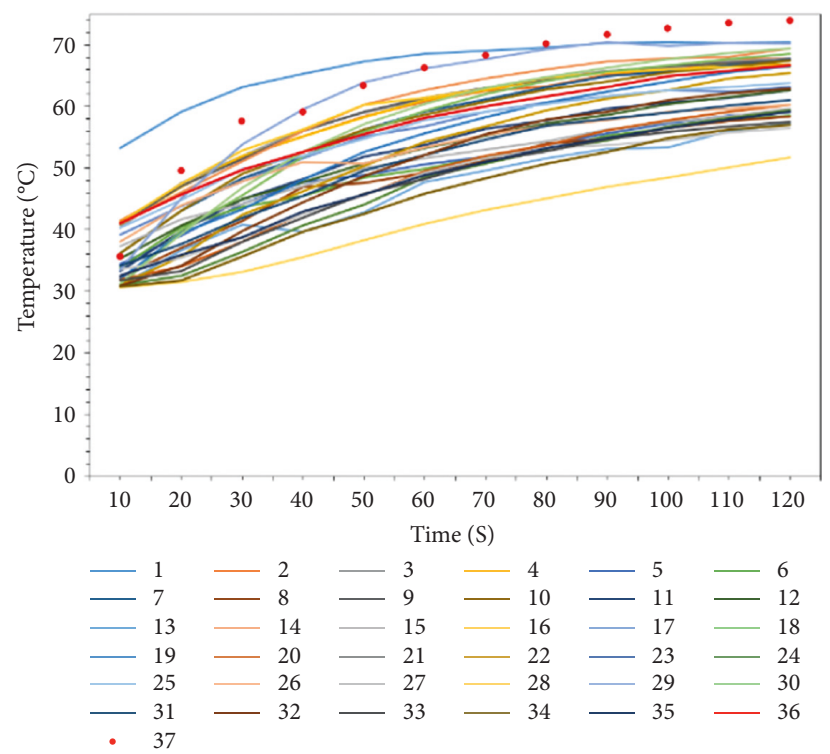

(a)
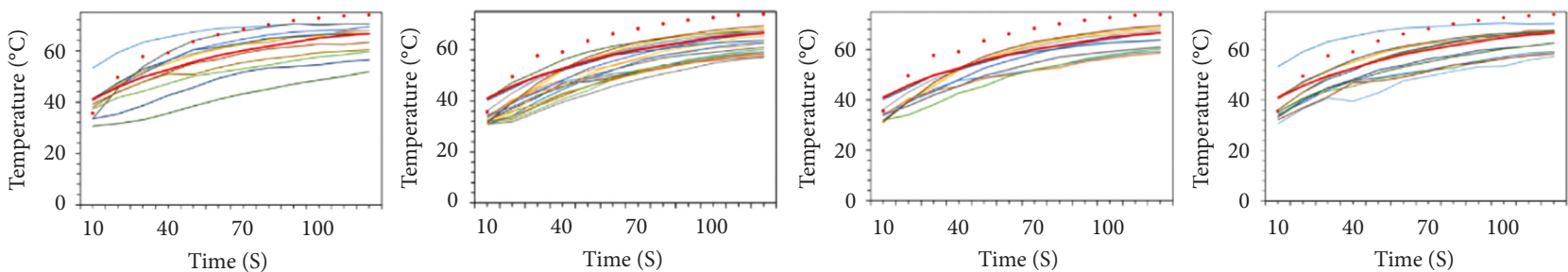
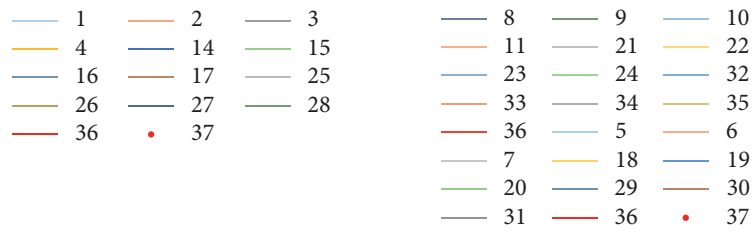

(c)

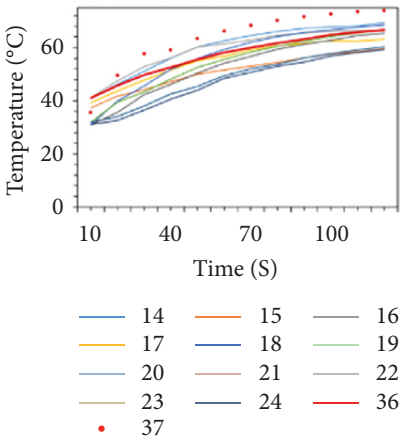

(f)

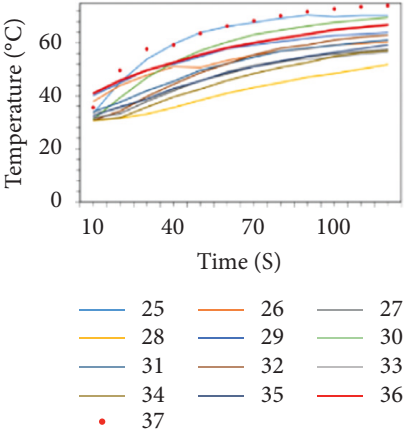

(g)

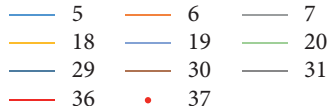

(d)

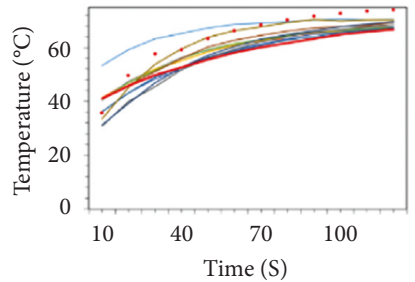

$\begin{array}{ccc}-1 & -2 & -3 \\ -7 & -3 \\ - & -10 & -14 \\ -14 & -18 \\ 25 & -30 & -36\end{array}$

(h)

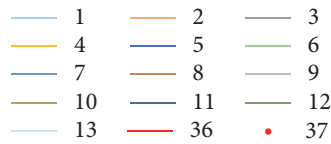

(e)

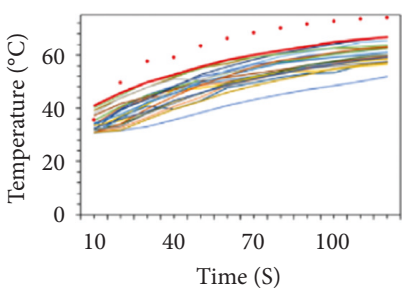

(i)

Figure 2: Thermal behavior of manufactured laminates. (a) General; (b) containing CF and NHF; (c) containing CF, GF, and NHF; (d) containing CF and GF; (e) containing $10 \mathrm{~g}$ of $\mathrm{Al}_{2} \mathrm{O}_{3}$; (f) containing $\mathrm{Al}$; (g) containing only resin; (h) with a temperature higher than that of sample 36; and (i) with a temperature lower than that of sample 36.

interaction in heat transfer are those shown in Figure 1(b). In the systems to be evaluated, two materials are built: The first one is shown in Figure 1(b), which is representative of the laminate constructed with CF or GF or NHF, and its input variable for the simulation was the thermal conductivity obtained experimentally. The second is the air that surrounds the laminate, and its thermal conductivity was obtained from the ANSYS database. Finally, in Figure 1(c), the meshing of the 
system is shown considering a body sizing of $8 \times 10^{-2} \mathrm{~m}$ for the bonnet, roof, and both rear doors, $6 \times 10^{-2} \mathrm{~m}$ for both front doors and boot, and $7 \times 10^{-2} \mathrm{~m}$ for air.

\section{Results and Discussion}

The solar radiation was $981 \mathrm{~W} \cdot \mathrm{m}^{-2}$ at an ambient temperature of $32.2^{\circ} \mathrm{C}$, which is relatively high. The surface temperature of the car increases due to solar radiation, and the temperature was particularly high considering that May 31, 2018, was one of the hottest days. Then, the main heat transfer is by convection, considering steady state, unidirectional flow, and a convective constant of air of $20.5 \mathrm{~W} \cdot \mathrm{m}^{-2} \cdot \mathrm{K}^{-1}$. So, on the basis of these data, the theoretical temperature on the surface was $80^{\circ} \mathrm{C}$.

For the determination of the thermal behavior of the laminates, each laminate was exposed to the hot surface $\left(80^{\circ} \mathrm{C}\right.$, the theoretical value of the surface), on the back part of the laminate, and the temperature values of the upper part of the surface are shown in Figure 2. Figure 2(a) shows the results of the thermal behavior for the laminates described in Section 2, with all the possible combinations of laminates (Table 1). It was considered that the heat transfer of the experiment was by conduction. Figure 2(b) shows the thermal behavior, considering all laminates manufactured with $\mathrm{CF}, \mathrm{NHF}$, and the reference laminates (samples 36 and 37). The highest heat transfer was found in samples 1,25 , and 14 , which were laminates manufactured only with CF. The highest thermal resistance that was the objective of the investigation was present in samples 15, 27, and 28 that did not contain additives $\left(\mathrm{Al}_{2} \mathrm{O}_{3}\right.$ or $\left.\mathrm{Al}\right)$. The additive $\mathrm{Al}_{2} \mathrm{O}_{3}$ increases the thermal conductivity more than the $\mathrm{Al}$, as with sample 1 (containing $\mathrm{Al}_{2} \mathrm{O}_{3}$ ) a temperature of $70.04^{\circ} \mathrm{C}$ and with sample 14 (containing $\mathrm{Al}$ ) a temperature of $69.4^{\circ} \mathrm{C}$ were recorded. By grouping the results of the $\mathrm{CF}, \mathrm{NHF}$, and GF laminates (Figure 2(c)), the one with the highest thermal resistance is sample 34, which contains laminated GF at the ends. Again, the observed phenomenon was that the $\mathrm{Al}_{2} \mathrm{O}_{3}$ additive improved thermal conductivity. Figure $2(\mathrm{~d})$ is for CF and GF laminates, where the highest thermal resistance was for sample 6, which contained three layers of CF and two layers of $\mathrm{GF}$.

Figure 2(e) shows the thermal behavior considering that all the laminates contained the additive $\mathrm{Al}_{2} \mathrm{O}_{3}$. The results show that the greater the number of CF layers, the greater the thermal conductivity (sample 1) and that the best thermal barrier is the combination of sample 13 that contains CF, GF, and NHF. Now, grouping the laminates containing $\mathrm{Al}$ (Figure 2(f)) confirms that the highest thermal conductivity occurs in laminates containing CF (sample 14) and the highest thermal resistance occurs with CF, GF, and NHF laminates (sample 24). Considering the laminates that were embedded only in the resin (Figure 2(g)), the highest thermal resistance is present in sample 28. If the materials that exceed the thermal conductivity of stainless steel are considered (Figure 2(h)), the laminate of sample 1 would be indicated to simulate. The best laminates that behave as a thermal barrier, taken as reference sample 36 (Figure 2(i)), were samples 28,27 , and 34 . Sample 34 contains glass fibers,
TABLE 2: Thermal conductivities of the laminates, inferior to the thermal conductivity of sample 36 .

\begin{tabular}{lc}
\hline Sample & $\mathrm{K} / \mathrm{W} \cdot \mathrm{m}^{-1} \cdot \mathrm{K}^{-1}$ \\
\hline$* 5$ & 7.41 \\
6 & 7.13 \\
8 & 7.09 \\
11 & 9.17 \\
12 & 9.17 \\
13 & 6.69 \\
15 & 7.58 \\
${ }^{*} 17$ & 9.58 \\
19 & 12.66 \\
20 & 7.88 \\
22 & 11.44 \\
24 & 7.47 \\
26 & 7.90 \\
27 & 6.41 \\
${ }^{*} 28$ & 5.22 \\
29 & 10.02 \\
$* 31$ & 8.26 \\
32 & 9.40 \\
33 & 6.77 \\
34 & 6.60 \\
35 & 7.41 \\
$* 36$ & 12.90 \\
$* 37$ & 13.43 \\
\hline
\end{tabular}

* Better thermal barrier.

and then it would be advisable not to consider this as a more ecological laminate than that containing only CF and NHF. The results of the thermal conductivity are shown in Table 2, which correspond to the laminates that are considered as thermal barriers shown in Figure 2(i).

The simulated temperature profiles are shown in Figure 3, considering the conductivity results for samples $* 5,{ }^{*} 17,{ }^{*} 28$, ${ }^{*} 31, * 36$, and $* 37$, with the results of the average temperature on the upper surface, given each sample at $120 \mathrm{~s}$.

In the processing of data for decision making, there are simulation tools that are very important to use, before building a final prototype. Sample 37 recorded an experimental temperature average of $73.92^{\circ} \mathrm{C}$ at $120 \mathrm{~s}$ (Figure 2), and the results of the simulation (Figure 3(a)) show a temperature of $73.87^{\circ} \mathrm{C}$, close to the experimental value. For samples $36,17,31,5$, and 28 , the experimental temperatures were $66.73^{\circ} \mathrm{C}, 63.20^{\circ} \mathrm{C}, 61.02^{\circ} \mathrm{C}, 59.20^{\circ} \mathrm{C}$, and $51.79^{\circ} \mathrm{C}$ (Figure 2), respectively. The temperatures obtained in the simulation were $67.12^{\circ} \mathrm{C}, 63.66^{\circ} \mathrm{C}, 61.22^{\circ} \mathrm{C}, 59.37^{\circ} \mathrm{C}$, and $51.53^{\circ} \mathrm{C}$, respectively. Also, the values for the simulations were very close to those of the experimental ones. Considering the material from which the roof of a car is manufactured, the internal temperature would be $62.34^{\circ} \mathrm{C}$ (Figure 3(a)). If the material used was stainless steel (sample 36), the air inside the car would be $57.09^{\circ} \mathrm{C}$ (Figure 3(b)). The temperature decreases to $54.40^{\circ} \mathrm{C}$ (Figure 3(c)), when using NHF/CF/NHF/CF/NHF mixed with $\mathrm{Al}$ due to the insertion of the NHF. In the case of having a laminate of $\mathrm{GF} / \mathrm{CF} / \mathrm{GF} / \mathrm{CF} / \mathrm{GF}$, the temperature was $52.51^{\circ} \mathrm{C}$ (Figure $3(\mathrm{~d})$ ) by the insertion of the GF. Then, having an additive of $\mathrm{Al}_{2} \mathrm{O}_{3}$ in a $\mathrm{CF} / \mathrm{CF} / \mathrm{GF} / \mathrm{CF} / \mathrm{CF}$ laminate allows having a temperature of $51.06^{\circ} \mathrm{C}$ (Figure $3(\mathrm{e})$ ). 

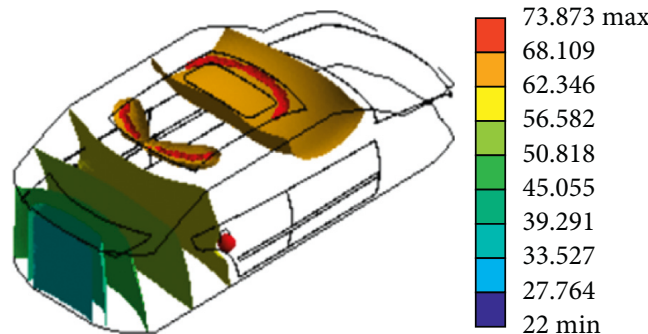

(a)
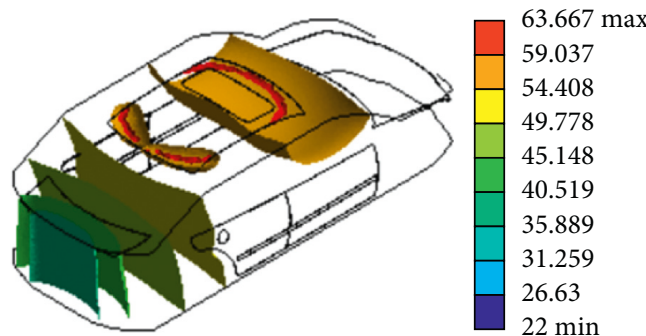

(c)

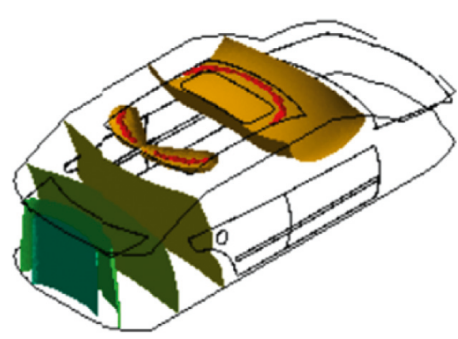

(e)

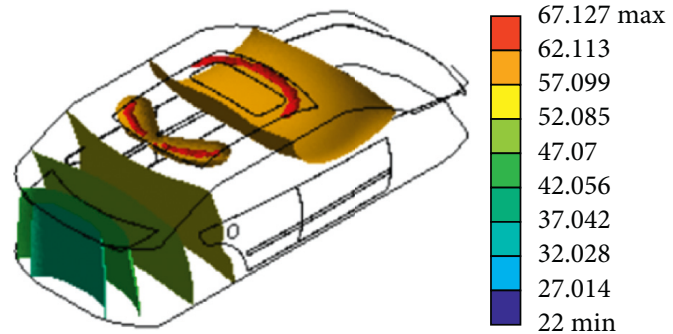

(b)

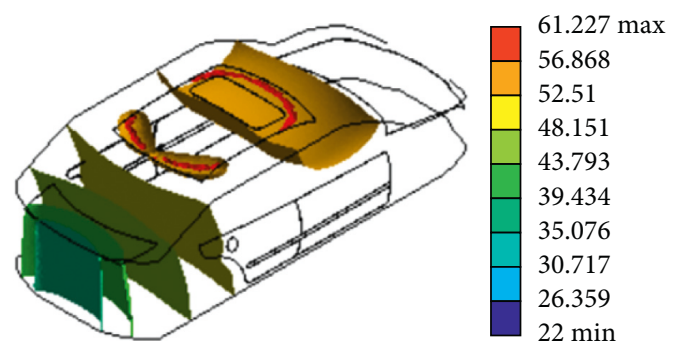

(d)

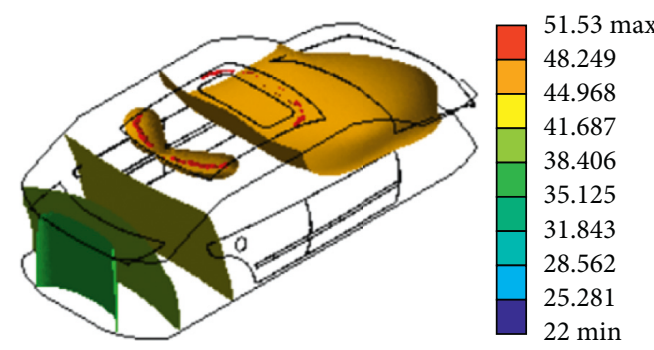

(f)

Figure 3: Temperature profiles $\left({ }^{\circ} \mathrm{C}\right)$ for (a) reference sample 37 and (b) sample 36 and for the laminates considered as thermal barriers: (c) sample *17, (d) sample ${ }^{*} 31$, (e) sample ${ }^{*} 5$, and (f) sample ${ }^{*} 28$.

Finally, the best thermal barrier was the laminate built with $\mathrm{NHF} / \mathrm{CF} / \mathrm{NHF} / \mathrm{CF} / \mathrm{NHF}$ (Figure 3(f)), registering an operating temperature of $44.96^{\circ} \mathrm{C}$ due to the $\mathrm{NHF}$; that is, it allows generating a temperature difference of $17.37^{\circ} \mathrm{C}$ inside the car.

The morphology of the materials used is shown in Figure 4(a), where the best thermal barrier was obtained with sample 28 that was formed with $\mathrm{NHF} / \mathrm{CF} / \mathrm{NHF} / \mathrm{CF} /$ NHF, as shown in Figure 4(b). The evaluation of morphology was made using scanning electron microscopy as shown in Figure 4(c). The three white parts (edges and center) are NHF, and the dark part in the center of the NHF is the CF, which are homogeneously integrated into a piece. Increasing the magnification to $300 \mathrm{x}$, the NHF is shown in Figure 4(d), and the results of the elemental composition were obtained by energy-dispersive $\mathrm{X}$-ray spectroscopy (EDS). The NHF has an elongated laminar morphology, similar to the CF shown in Figure 4(e). The lamination of the roof was formed by Fe (87.28 wt.\%) and C (12.72 wt.\%).

\section{Conclusions}

The interesting finding is that the carbon fiber laminates either combined with resin $+\mathrm{Al}_{2} \mathrm{O}_{3}$, resin $+\mathrm{Al}$, or only resin always remain above sample 36, highlighting the property of thermal conductivity of carbon fiber. On the contrary, as regards the thermal behavior of the GF, it was observed that a third of the nine laminates have better thermal behavior than sample 36. Therefore, in this case, GF did not act as a thermal barrier in this composite. It can be seen that, of the three laminates with higher thermal conductivity, only sample 36 (CF/GF/CF/GF/CF) was combined with resin. The results show that including the additive (resin $+\mathrm{Al}$ or resin $+\mathrm{Al}_{2} \mathrm{O}_{3}$ ) did not contribute significantly to the thermal conductivity of the material.

The thermal barrier obtained was made with $\mathrm{NHF} / \mathrm{CF} /$ NHF/CF/NHF (sample 28), which only added resin, and presented an experimental thermal conductivity of $5.22 \mathrm{~W} \cdot \mathrm{m}^{-1} \cdot \mathrm{K}^{-1}$. This is $61.13 \%$ lower than the conductivity of the material with which the roof of a car is formed (sample 37). Thus, the material that provides the characteristic thermal barrier was the NHF.

The simulation of the process of heat transfer allows deducing that, if the roof of a car is manufactured with the proposed compound (sample 28), there would be a decrease in temperature from $62.34^{\circ} \mathrm{C}$ to $44.24^{\circ} \mathrm{C}$. This implies that the proposed compound significantly lowers the internal temperature of the car by $29.03 \%$. This temperature difference could have an effect on fuel savings by lowering the use of air 


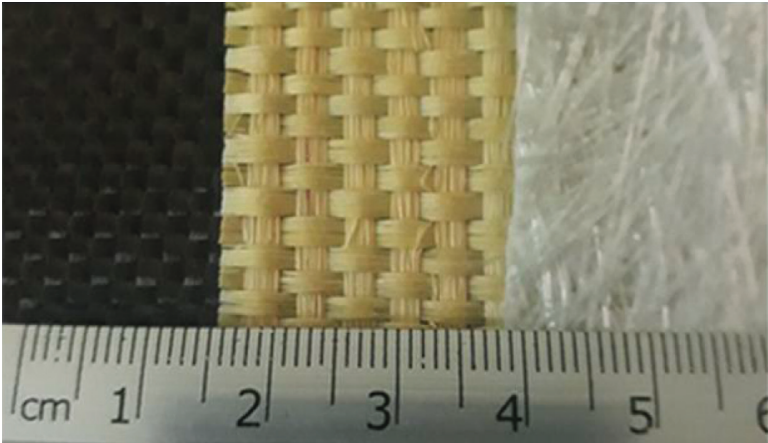

(a)

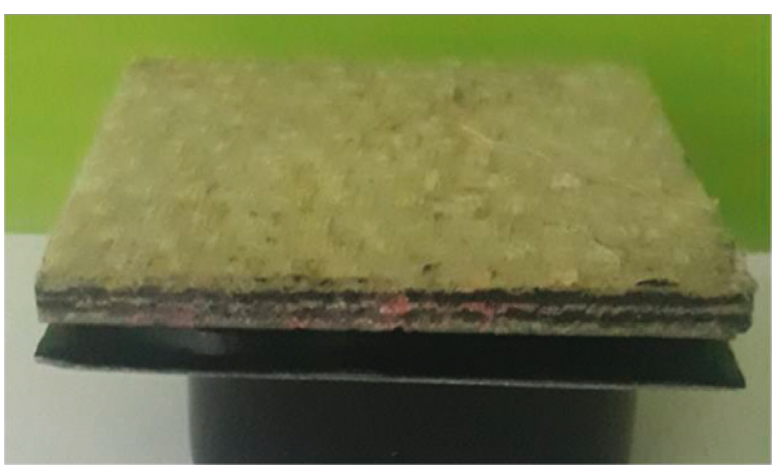

(c)

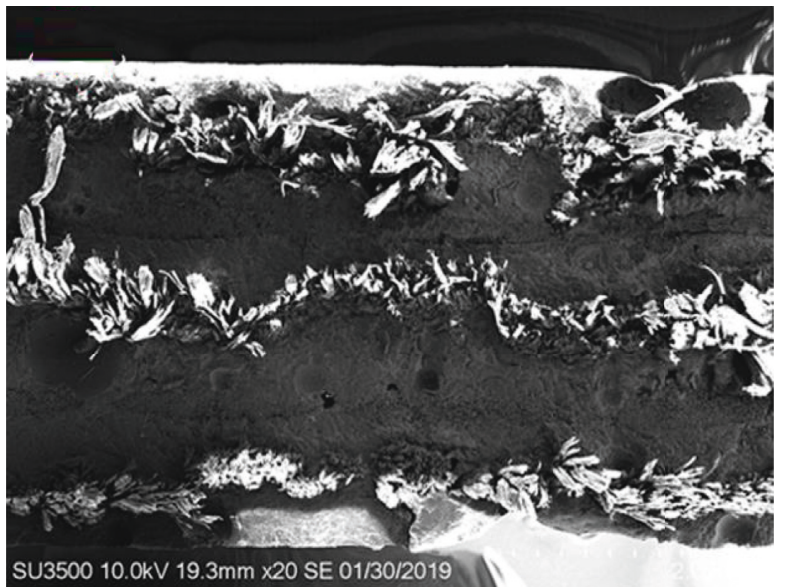

(e)

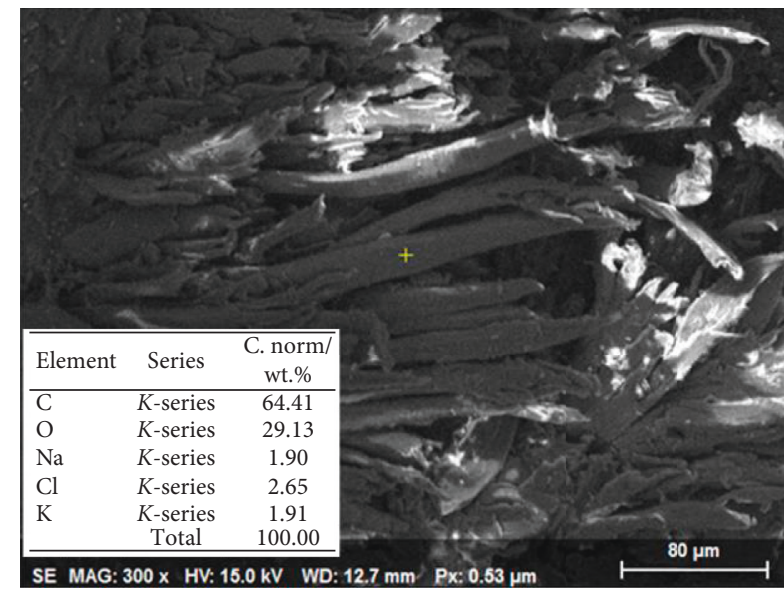

(b)

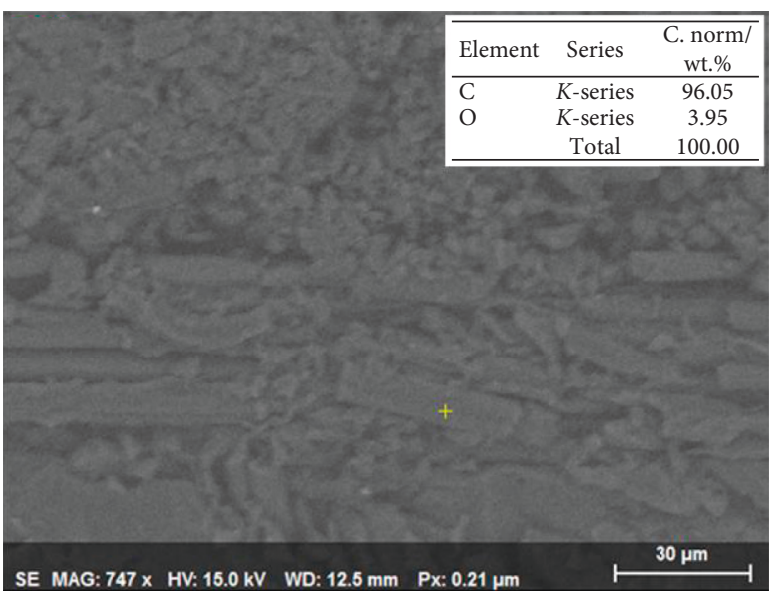

(d)

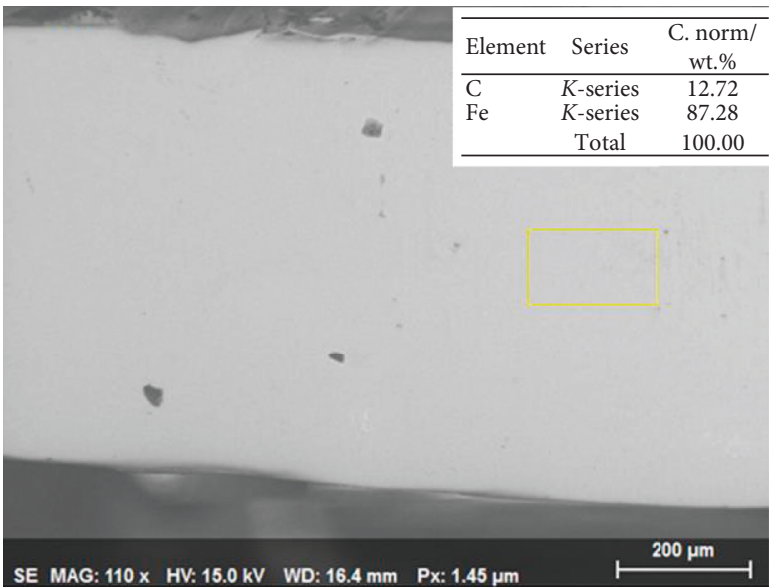

(f)

Figure 4: Images of the materials used (a) CF, NHF, and GF, (b) sample 28 and sheet of the roof, (c) SEM of sample 28, (d) morphology and composition of the NHF, (e) morphology and composition of the CF, and (f) morphology and composition of the sheet of roof.

conditioning for a shorter period to keep a comfortable temperature since the heat to be removed would be $29.03 \%$ lower.

In general, the current manufacturing process of a car roof is through a hydraulic process and high precision molds. However, the composite material manufacturing process, that is, proposed in this research, requires less economic and energy investments.

\section{Data Availability}

No data were used to support this study. 


\section{Conflicts of Interest}

The authors declare that there are no conflicts of interest regarding the publication of this paper.

\section{Acknowledgments}

The authors thank Iván Josue Valencia Gómez, José Carlos Ramírez Baltazar, and Francisco Javier Cruz Pérez for technical support. The authors thank CONACYT for financial support through "Cátedra CONACyT" project (513) and FOMIX project (279788).

\section{References}

[1] P. Sharma, D. Khanduja, and S. Sharma, "Tribological and mechanical behavior of particulate aluminum matrix composites," Journal of Reinforced Plastics and Composites, vol. 33, no. 23, pp. 2192-2202, 2014.

[2] A. Kelly, "Composite materials after seventy years," Journal of materials science, vol. 41, no. 3, pp. 905-912, 2006.

[3] C. S. Ramesh, H. Adarsha, S. Pramod, and Z. Khan, "Tribological characteristics of innovative Al6061-carbon fiber rod metal matrix composites," Materials \& Design, vol. 50, pp. 597-605, 2013.

[4] G. Lalet, H. Kurita, J. M. Heintz, G. Lacombe, A. Kawasaki, and J. F. Silvain, "Thermal expansion coefficient and thermal fatigue of discontinuous carbon fiber-reinforced copper and aluminum matrix composites without interfacial chemical bond," Journal of Materials Science, vol. 49, no. 1, pp. 397-402, 2014.

[5] S. H. Cho, "Heat dissipation effect of $\mathrm{Al}$ plate embedded substrate in a network system," Microelectronics Reliability, vol. 48, no. 10, pp. 1696-1702, 2008.

[6] J. D. Mathias, P. M. Geffroy, and J. F. Silvain, "Architectural optimization for microelectronic packaging," Applied Thermal Engineering, vol. 29, no. 11-12, pp. 2391-2395, 2009.

[7] J. F. Silvain, C. Vincent, J. M. Heintz, and N. Chandra, "Novel processing and characterization of $\mathrm{Cu} / \mathrm{CNF}$ nanocomposite for high thermal conductivity applications," Composites Science and Technology, vol. 69, no. 14, pp. 2474-2484, 2009.

[8] M. Lee, Y. Choi, K. Sugio, K. Matsugi, and G. Sasaki, "Effect of aluminum carbide on thermal conductivity of the unidirectional CF/Al composites fabricated by low pressure infiltration process," Composites Science and Technology, vol. 97, pp. 1-5, 2014.

[9] A. Veillère, J.-M. Heintz, N. Chandra et al., "Influence of the interface structure on the thermo-mechanical properties of $\mathrm{Cu}-\mathrm{X}(\mathrm{X}=\mathrm{Cr}$ or $\mathrm{B}) /$ carbon fiber composites," Materials Research Bulletin, vol. 47, no. 2, pp. 375-380, 2012.

[10] C. Liu, M. Chen, W. Yu, and Y. He, "Recent advance on graphene in heat transfer enhancement of composites," Energy \& Environmental Science, vol. 2, pp. 31-42, 2018.

[11] X. Jia, G. Hu, F. Nitze et al., "Synthesis of palladium/helical carbon nanofiber hybrid nanostructures and their application for hydrogen peroxide and glucose detection," ACS Applied Materials \& Interfaces, vol. 5, no. 22, pp. 12017-12022, 2013.

[12] P. Morgan, Carbon Fibers and Their Composites, CRC Press, Boca Raton, FL, USA, 2005.

[13] D. D. Edie, "The effect of processing on the structure and properties of carbon fibers," Carbon, vol. 36, no. 4, pp. 345$362,1998$.
[14] A. Rodríguez-Guerrero, S. A. Sanchez, J. Narciso, E. Louis, and F. Rodríguez-Reinoso, "Pressure infiltration of Al-12 wt.\% $\mathrm{Si}-\mathrm{X}(\mathrm{X}=\mathrm{Cu}, \mathrm{Ti}, \mathrm{Mg})$ alloys into graphite particle preforms," Acta Materialia, vol. 54, no. 7, pp. 1821-1831, 2006.

[15] W. G. Wang, B. L. Xiao, and Z. Y. Ma, "Evolution of interfacial nanostructures and stress states in $\mathrm{Mg}$ matrix composites reinforced with coated continuous carbon fibers," Composites Science and Technology, vol. 72, no. 2, pp. 152-158, 2012.

[16] H. Khayyam, M. Naebe, O. Zabihi, R. Zamani, S. Atkiss, and B. Fox, "Dynamic prediction models and optimization of polyacrylonitrile (PAN) stabilization processes for production of carbon fiber," IEEE Transactions on Industrial Informatics, vol. 11, no. 4, pp. 887-896, 2015.

[17] S. Chand, "Review carbon fibers for composites," Journal of materials science, vol. 35, no. 6, pp. 1303-1313, 2000.

[18] L. Xia, B. Jia, J. Zeng, and J. Xu, "Wear and mechanical properties of carbon fiber reinforced copper alloy composites," Materials Characterization, vol. 60, no. 5, pp. 363-369, 2009.

[19] E. Fitzer, "Pan-based carbon fibers-present state and trend of the technology from the viewpoint of possibilities and limits to influence and to control the fiber properties by the process parameters," Carbon, vol. 27, no. 5, pp. 621-645, 1989.

[20] M. Minus and S. Kumar, "The processing, properties, and structure of carbon fibers," Jom, vol. 57, no. 2, pp. 52-58, 2005.

[21] V. V. Kozey, H. Jiang, V. R. Mehta, and S. Kumar, "Compressive behavior of materials: Part II. High performance fibers," Journal of Materials Research, vol. 10, no. 4, pp. 1044-1061, 1995.

[22] Y. Liu and S. Kumar, "Recent progress in fabrication, structure, and properties of carbon fibers," Polymer Reviews, vol. 52, no. 3, pp. 234-258, 2012.

[23] Z. Jun, X. Jincheng, H. Wei et al., "Wear performance of the lead-free tin bronze matrix composite reinforced by short carbon fibers," Applied Surface Science, vol. 255, no. 13-14, pp. 6647-6651, 2009.

[24] S.-J. Park and M.-S. Cho, "Effect of anti-oxidative filler on the interfacial mechanical properties of carbon-carbon composites measured at high temperature," Carbon, vol. 38, no. 7, pp. 1053-1058, 2000.

[25] H. Z. S. M. Naji, S. M. Zebarjad, and S. A. Sajjadi, “The effects of volume percent and aspect ratio of carbon fiber on fracture toughness of reinforced aluminum matrix composites," Materials Science and Engineering: A, vol. 486, no. 1-2, pp. 413-420, 2008.

[26] C. S. Ramesh and T. B. Prasad, "Friction and wear behavior of graphite-carbon short fiber reinforced $\mathrm{Al}-17 \%$ Si alloy hybrid composites," Journal of Tribology, vol. 131, no. 1, article 014501, 2009.

[27] L. Liu, W. Li, Y. Tang, B. Shen, and W. Hu, "Friction and wear properties of short carbon fiber reinforced aluminum matrix composites," Wear, vol. 266, no. 7-8, pp. 733-738, 2009.

[28] V. K. Thakur, M. K. Thakur, and R. K. Gupta, "Review: raw natural fiber-based polymer composites," International Journal of Polymer Analysis and Characterization, vol. 19, no. 3, pp. 256-271, 2014.

[29] H. Ku, H. Wang, N. Pattarachaiyakoop, and M. Trada, “A review on the tensile properties of natural fiber reinforced polymer composites," Composites Part B: Engineering, vol. 42, no. 4, pp. 856-873, 2011.

[30] B. Barari, T. K. Ellingham, I. Qamhia et al., "Mechanical characterization of scalable cellulose nano-fiber based composites made using liquid composite molding process," Composites Part B: Engineering, vol. 84, pp. 277-284, 2016. 
[31] C. Unterweger, O. Brüggemann, and C. Fürst, "Synthetic fibers and thermoplastic short-fiber-reinforced polymers: properties and characterization," Polymer Composites, vol. 35, no. 2, pp. 227-236, 2014.

[32] P. L. Menezes, P. K. Rohatgi, and M. R. Lovell, "Studies on the tribological behavior of natural fiber reinforced polymer composite," in Green Tribology, pp. 329-345, Springer, Berlin, Gemany, 2012.

[33] D. B. Dittenber and H. V. S. GangaRao, "Critical review of recent publications on use of natural composites in infrastructure," Composites Part A: Applied Science and Manufacturing, vol. 43, no. 8, pp. 1419-1429, 2012.

[34] W. D. Brouwer, "Natural fiber composites: where can flax compete with glass?," Sampe Journal, vol. 36, no. 6, pp. 18-23, 2000.

[35] T. F. A. Santos, G. C. Vasconcelos, W. A. de Souza, M. L. Costa, and E. C. Botelho, "Suitability of carbon fiberreinforced polymers as power cable cores: galvanic corrosion and thermal stability evaluation," Materials \& Design, vol. 65, pp. 780-788, 2015

[36] X. Q. Pei, R. Bennewitz, and A. K. Schlarb, "Mechanisms of friction and wear reduction by carbon fiber reinforcement of PEEK," Tribology Letters, vol. 58, no. 3, p. 42, 2015.

[37] S. Bahadur and Y. Zheng, "Mechanical and tribological behavior of polyester reinforced with short glass fibers," Wear, vol. 137, no. 2, pp. 251-266, 1990.

[38] S. W. Zhang, "State-of-the-art of polymer tribology," Tribology International, vol. 31, no. 1-3, pp. 49-60, 1998.

[39] K. Friedrich, Z. Zhang, and A. K. Schlarb, "Effects of various fillers on the sliding wear of polymer composites," Composites Science and Technology, vol. 65, no. 15-16, pp. 2329-2343, 2005.

[40] D. L. Burris, B. Boesl, G. R. Bourne, and W. G. Sawyer, "Polymeric nanocomposites for tribological applications," Macromolecular Materials and Engineering, vol. 292, no. 4, pp. 387-402, 2007.

[41] Y. Zhang, S. Zhu, Y. Liu, B. Yang, and X. Wang, "The mechanical and tribological properties of nitric acid-treated carbon fiber-reinforced polyoxymethylene composites," Journal of Applied Polymer Science, vol. 132, no. 15, 2015.

[42] H. N. Dhakal, Z. Y. Zhang, R. Guthrie, J. MacMullen, and N. Bennett, "Development of flax/carbon fibre hybrid composites for enhanced properties," Carbohydrate Polymers, vol. 96, no. 1, pp. 1-8, 2013.

[43] V. K. Thakur, A. S. Singha, and I. K. Mehta, "Renewable resource-based green polymer composites: analysis and characterization," International Journal of Polymer Analysis and Characterization, vol. 15, no. 3, pp. 137-146, 2010.

[44] C. Alves, P. M. C. Ferrão, A. J. Silva et al., "Ecodesign of automotive components making use of natural jute fiber composites," Journal of Cleaner Production, vol. 18, no. 4, pp. 313-327, 2010.

[45] M. John and S. Thomas, "Biofibres and biocomposites," Carbohydrate polymers, vol. 71, no. 3, pp. 343-364, 2008.

[46] A. Bismarck, I. Aranberri-Askargorta, J. Springer et al., "Surface characterization of natural fibers; surface properties and the water up-take behavior of modified sisal and coir fibers," Green Chemistry, vol. 3, no. 2, pp. 100-107, 2001.

[47] G. Xie, D. Ding, and G. Zhang, "Phonon coherence and its effect on thermal conductivity of nanostructures," Advances in Physics: X, vol. 3, no. 1, pp. 719-754, article 1480417, 2018.

[48] A. Hazarika, B. K. Deka, D. Kim, H. E. Jeong, Y.-B. Park, and H. W. Park, "Woven Kevlar fiber/polydimethylsiloxane/reduced graphene oxide composite-based personal thermal management with freestanding $\mathrm{Cu}-\mathrm{Ni}$ core-shell nanowires," Nano Letters, vol. 18, no. 11, pp. 6731-6739, 2018.

[49] P. Baumli, J. Sychev, I. Budai, J. T. Szabo, and G. Kaptay, "Fabrication of carbon fiber reinforced aluminum matrix composites via a titanium-ion containing flux," Composites Part A: Applied Science and Manufacturing, vol. 44, pp. 47-50, 2013.

[50] Y. Arao, S. Yumitori, H. Suzuki, T. Tanaka, K. Tanaka, and T. Katayama, "Mechanical properties of injection-molded carbon fiber/polypropylene composites hybridized with nanofillers," Composites Part A: Applied Science and Manufacturing, vol. 55, pp. 19-26, 2013.

[51] K. Lawrence, ANSYS Workbench Tutorial Release 11, Schroff Development Corporation, Straubenhardt, Germany, 2007, https://dl.acm.org/citation.cfm?id=1537215ANSYS. 


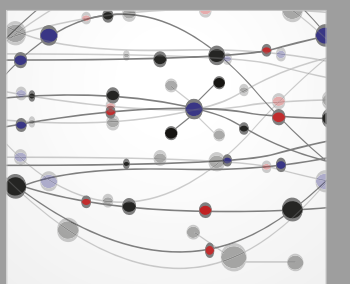

The Scientific World Journal
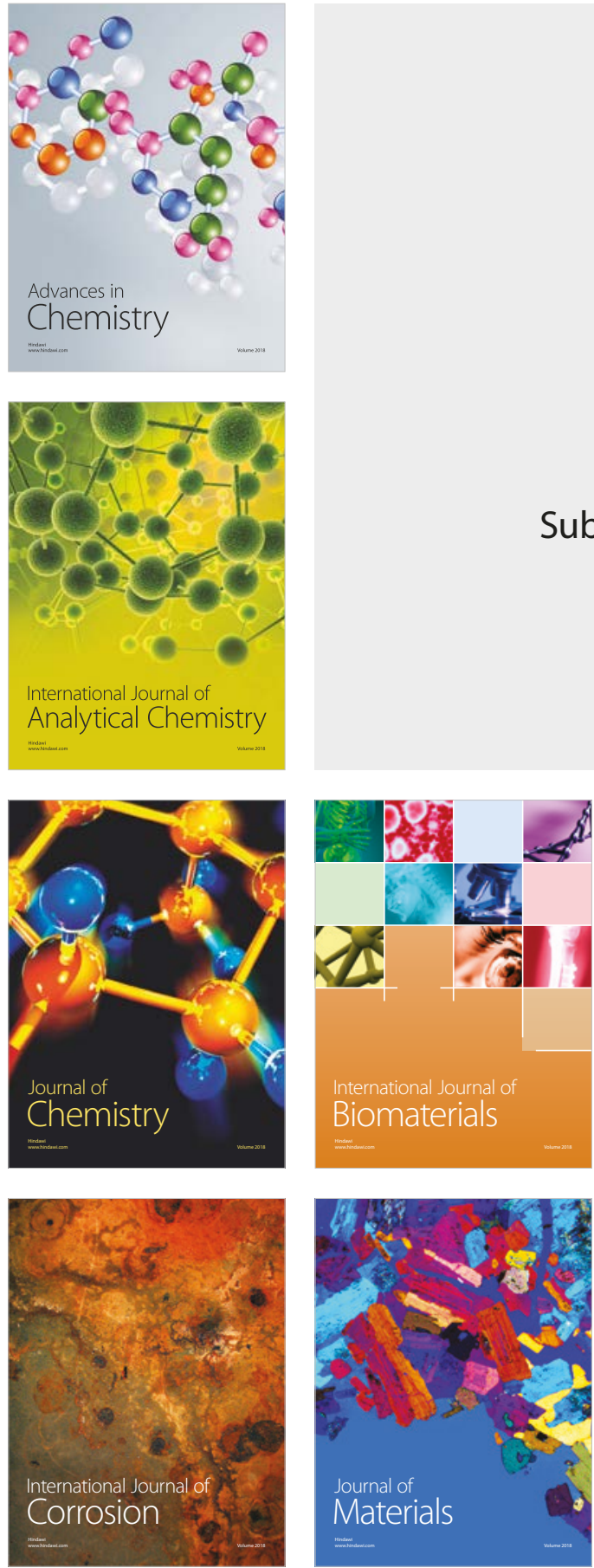

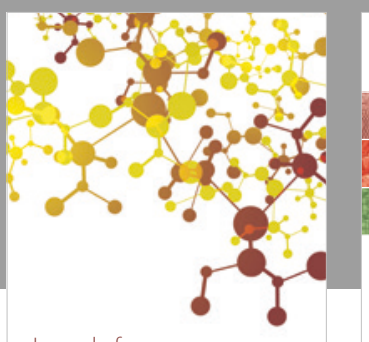

Journal of

Applied Chemistry
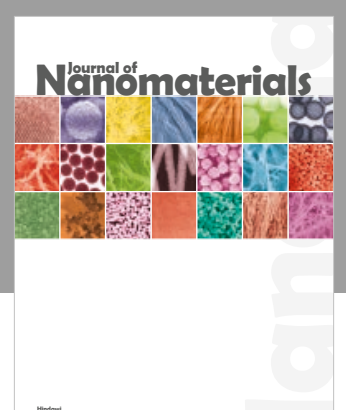

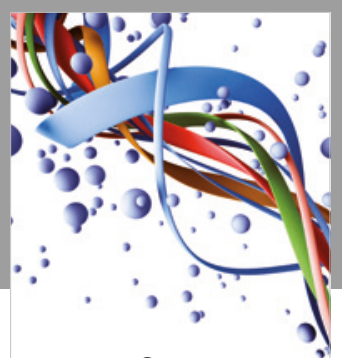

Scientifica

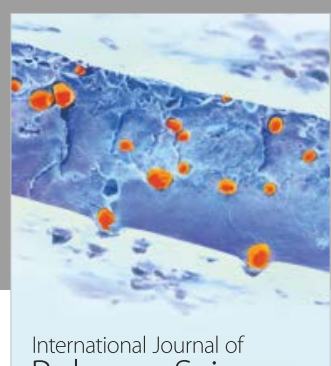

Polymer Science

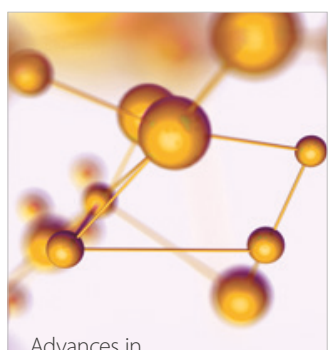

Physical Chemistry
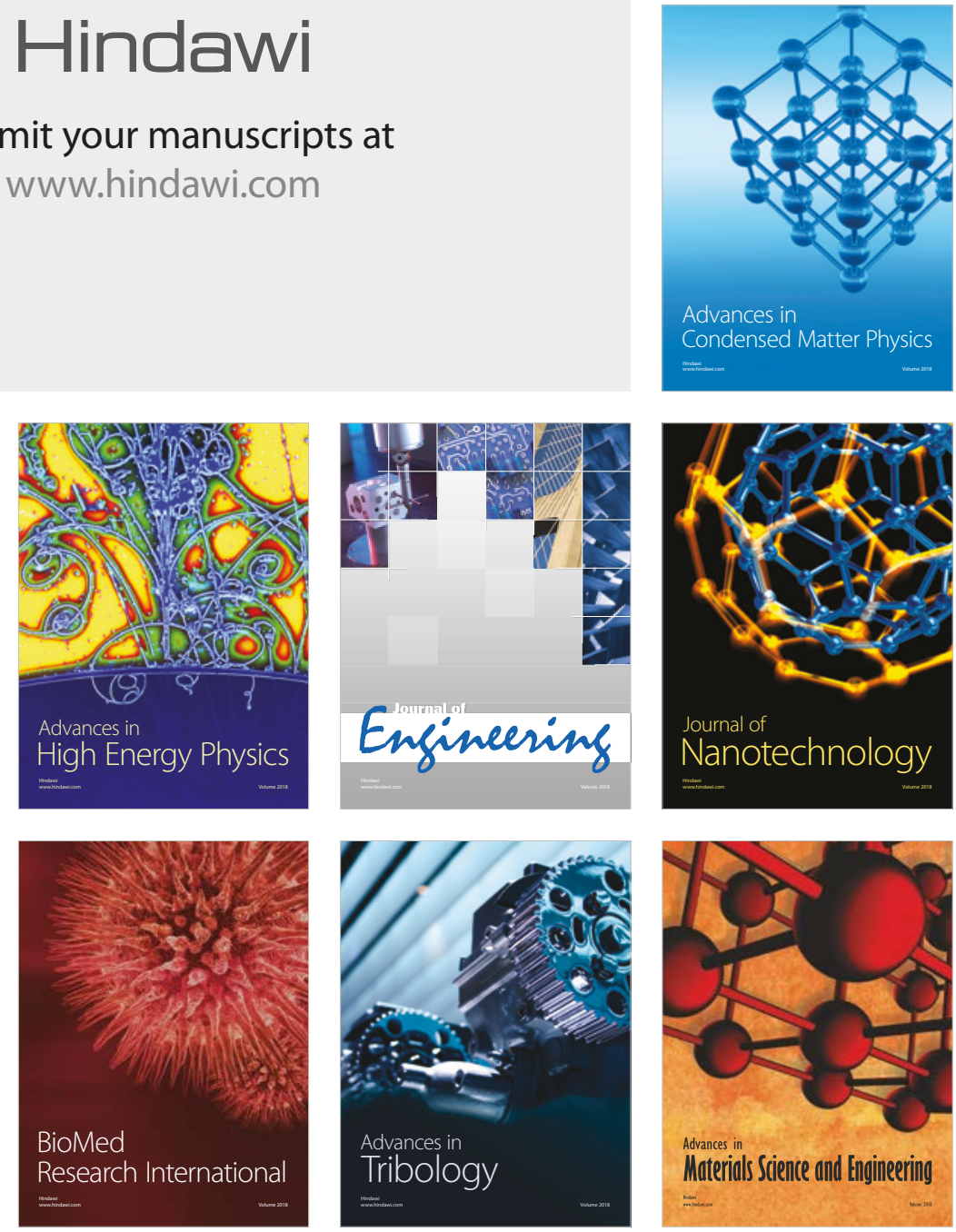